\title{
Molecular mapping of the regenerative niche in a murine model of myocardial infarction
}

\author{
GABRIELA DORNELLES ALVES ${ }^{1}$, MARIANA PAZZINE ${ }^{2}$, LUISA MARIA GOMES DE MACEDO BRAGA ${ }^{3}$, \\ MARIA CLÁUDIA IRIGOYEN ${ }^{2}$, KÁTIA DE ANGELIS ${ }^{2}$, NILO IKUTA ${ }^{1}$, \\ MELISSA CAMASSOLA ${ }^{1}$ and NANCE BEYER NARDI ${ }^{1}$ \\ ${ }^{1}$ Laboratory of Stem Cells and Tissue Engineering, Lutheran University Brazil, Av. Farroupilha 8001, 92425-900 Canoas, RS; \\ ${ }^{2}$ Hypertension Unit, Heart Institute, São Paulo University, Av. Dr Eneas Carvalho de Aguiar 44, 05403-904 São Paulo, SP; \\ ${ }^{3}$ Cardiology Institute, Cardiology University Foundation Rio Grande do Sul, \\ Av. Princesa Isabel 370, 90620-000 Porto Alegre, RS, Brazil
}

Received August 19, 2011; Accepted October 5, 2011

DOI: $10.3892 / \mathrm{ijmm} .2011 .850$

\begin{abstract}
Adult stem cells are distributed through the whole organism, and present a great potential for the therapy of different types of disease. For the design of efficient therapeutic strategies, it is important to have a more detailed understanding of their basic biological characteristics, as well as of the signals produced by damaged tissues and to which they respond. Myocardial infarction (MI), a disease caused by a lack of blood flow supply in the heart, represents the most common cause of morbidity and mortality in the Western world. Stem cell therapy arises as a promising alternative to conventional treatments, which are often ineffective in preventing loss of cardiomyocytes and fibrosis. Cell therapy protocols must take into account the molecular events that occur in the regenerative niche of MI. In the present study, we investigated the expression profile of ten genes coding for chemokines or cytokines in a murine model of MI, aiming at the characterization of the regenerative niche. MI was induced in adult $\mathrm{C} 57 \mathrm{BL} / 6$ mice and heart samples were collected after $24 \mathrm{~h}$ and 30 days, as well as from control animals, for quantitative RT-PCR. Expression of the chemokine genes CCL2, CCL3, CCL4, CCL7, CXCL2 and CXCL10 was significantly increased $24 \mathrm{~h}$ after infarction, returning to baseline levels on day 30. Expression of the CCL8 gene significantly increased only on day 30 , whereas gene expression of CXCL12 and CX3CL1 were not significantly increased in either ischemic period. Finally, expression of the IL-6 gene increased $24 \mathrm{~h}$ after infarction and was maintained at a significantly higher level than control samples 30 days later. These results contribute to the better knowledge of the regenerative niche in $\mathrm{MI}$, allowing a more efficient selection or genetic manipulation of cells in therapeutic protocols.
\end{abstract}

Correspondence to: Professor Nance Beyer Nardi, Laboratory of Stem Cells and Tissue Engineering, Universidade Luterana do Brasil, Av. Farroupilha 8001, 92425-900 Canoas, RS, Brazil E-mail: nancenardi@gmail.com

Key words: stem cells, regenerative niche, cytokines, chemokines, myocardial infarction

\section{Introduction}

The main function of adult stem cells is to maintain tissue homeostasis by replacing worn-out cells. Adult stem cells are also activated in response to signals of inflammation and tissue damage, and have an important role in the repair of tissues or organs (1). All adult tissues and organs have their own compartment of stem cells. Hematopoietic stem cells have been used for the therapy of hematologic diseases for over 40 years, and more recently adult stem cells have been intensively studied for their therapeutic potential in a great number of other diseases (2). Mesenchymal stem cells (MSC), which are distributed through the whole organism (3), have attracted attention due to their great therapeutic potential.

For the successful therapeutic use of stem cells, a more detailed understanding is necessary not only of their basic biological characteristics (4) but also of the regenerative niche. This will allow the design of therapeutic studies with cells able to respond appropriately to signs and to resist the lesion microenvironment, which is often unfavorable to them $(5,6)$.

Myocardial infarction (MI) is caused by a lack of blood supply to the heart muscle resulting in necrosis and triggering a cascade of events, involving several cell types and signalling molecules. This leads to inflammation and scarring with consequent tissue remodelling, as well as mechanical dysfunction and electrical conduction pathway abnormalities (7). MI is listed among the acute coronary syndromes that represent the most common cause of morbidity and mortality in the Western world. Currently, pharmacological, percutaneous and surgical treatments of ischemic cardiomyopathy are unable to prevent the loss of cardiomyocytes and fibrosis that is established (8). When ischemic disease is very advanced and diffuse, a condition affecting up to $12 \%$ of patients with ischemic heart disease, the available methods are not effective (9).

Cell therapy appears as a promising treatment for ischemic heart disease. The design of efficient therapeutic strategies must consider the molecular events which are present at the MI regenerative niche, so that the most appropriate cells can be selected to minimize the loss of cardiomyocytes and promote 
the return of normal function of the myocardium, through revascularization of ischemic zones and production of new cardiomyocytes (8).

Cytokines and chemokines play an important role in the recruitment of stem cells to the site of damage and in inducing their therapeutic responses (10). Soon after the lesion is produced, leukocytes are attracted and release inflammatory products that cause further tissue damage. The role of a number of them in the inflammatory condition that characterizes cardiovascular diseases such as atherosclerosis and MI has been described, but variable results are still seen in experimental and clinical studies $(11,12)$.

The molecular investigation of signalling molecules involved in intercellular interactions contributes to a better characterization of the regenerative niche in MI $(13,14)$. Although the mechanisms of action are not completely understood, the mapping of genes expressed in the ischemic heart over different periods is well advanced (15), and further exploration of the molecular profile of the regenerative niche is necessary as a first step in the design of protocols for cell therapy.

\section{Materials and methods}

Animals. Adult (8-10-week-old) male C57BL/6 mice, weighing around $25 \mathrm{~g}$, were maintained under standard conditions and treated in accordance with the Guidelines for the Care and Use of Laboratory Animals prepared by the National Academy of Sciences and published by the National Institutes of Health. All procedures were approved by a local Research Ethics Committee. This study was approved by the Research Ethics Committee of Universidade Luterana do Brasil.

Myocardial infarction. Myocardial infarction was induced in anaesthetized $(0.05 \mathrm{mg} / 100 \mathrm{~g}$ ketamine and $0.01 \mathrm{mg} / 100 \mathrm{~g}$ xylazine, intraperitoneally) mice by ligation of the left coronary artery with 7.0 prolene suture, as previously described (16) (Fig. 1A). Control mice were not operated, as previous studies showed no significant differences between non-operated and sham-operated animals (13).

Echocardiographic evaluation. Echocardiographic measurements were obtained under the recommendations of the American Society of Echocardiography $24 \mathrm{~h}$ after MI induction. The transthoracic echocardiogram was performed by using a Sequoia 512 (Acuson Corporation, Mountain View, CA), which offers a $10-13 \mathrm{MHz}$ multifrequency linear transducer. All measurements were based on the average of three consecutive cardiac cycles. Mice were anesthetized as described above. The ejection fraction [EF $(\%)=($ final diastolic volume-final systolic volume/final diastolic volume) x 100\%] was obtained by a modified Simpson's method, by the formula:

$$
V=\left[\frac{\pi}{4}\right] \sum_{\mathrm{r}-1}^{20} A_{1} B_{1} \times\left[\frac{L}{20}\right]
$$

where $\mathrm{L}=\mathrm{LV}$ length divided into 20 discs ( $\mathrm{i}=1$ to $1=20$ ) from basis to apex, with the diameter of each disc being determined in 2 apical views (denoted as A and B).

The MI akinetic area was delimited taking into account the movement of LV walls, by the observation of longitudinal, apical and transversal views of LV. Regions with systolic thickness under normal or absent, as well as, portions with paradoxal movement were considered as infarcted. Thus, the MI akinetic area (\%) was measured by the ratio of these regions by the total area of LV walls, as previously described by us and others $(17,18)$. Only animals with an EF $\leq 50 \%$ and infarcted area $\geq 30 \%$ were used in the experiments.

Molecular evaluation. A group of six mice were sacrificed $24 \mathrm{~h}$ after infarction, and a second group of 6 animals was sacrificed after 30 days. A third group of 6 healthy animals was used as control. The heart was arrested in diastole by perfusion with saline and collected. Samples from the left ventricle were collected, macerated, added into $1 \mathrm{ml}$ of TRIzol reagent (Invitrogen, Sao Paolo, SP, Brazil) and kept at $-20^{\circ} \mathrm{C}$ until RNA extraction, performed according to the supplier's instructions. After extraction, RNA was quantified using NanoDrop ND-1000 spectrophotometer and purity was determined by absorbance at $260 / 280 \mathrm{~nm}$.

cDNA synthesis was performed from $1 \mu \mathrm{g}$ of RNA, with oligo(dt) primers and the M-MLV Reverse Transcriptase kit (Invitrogen) using the Applied Biosystems Thermal Cycler Veriti. The expression of ten genes was assessed by quantitative real-time RT-PCR (qRT-PCR): interleukin 6 (IL-6), chemokine CXC motif ligand 2 (CXCL2), 10 (CXCL10) and 12 (CXCL12), chemokine CC motif ligand 2 (CCL2), 3 (CCL3), 4 (CCL4), 7 (CCL7), and 8 (CCL8), and chemokine CX3C motif ligand 1 (CX3CL1). The hypoxanthine-guanine phosphorybosiltransferase (HPRT) gene was used as an endogenous reference gene. The primers used were described in previous studies (Table I), except for CCL7 and HPRT, which were designed with FastPCR software. The CXCL12 isoform searched was the $\beta$ variant, the same which is present in kidney, but other isoforms can exist in heart.

The $25 \mu \mathrm{l}$ total volume PCR reaction mixture contained $12.5 \mu \mathrm{l}$ of 100 -fold diluted cDNA and the following reagents obtained from Invitrogen, in the following final concentrations: $1 X$ PCR buffer, $3 \mathrm{mM} \mathrm{MgCl}, 100 \mu \mathrm{M}$ dNTPs, $200 \mathrm{nM}$ of forward and reverse primers, 0.16X SYBR ${ }^{\circledR}$-Green, 0.25 units of Platinum Taq polymerase and $3.45 \mu 1$ of $\mathrm{H}_{2} \mathrm{O}$. The conditions for thermocycling were 1 cycle of $94^{\circ} \mathrm{C}$ for $5 \mathrm{~min}, 40$ cycles of $94^{\circ} \mathrm{C}$ for $15 \mathrm{sec}, 60^{\circ} \mathrm{C}$ for $10 \mathrm{sec}, 72^{\circ} \mathrm{C}$ for $15 \mathrm{sec}$ and $60^{\circ} \mathrm{C}$ for $35 \mathrm{sec}$, a cycle of dissociation of $95^{\circ} \mathrm{C}$ for $15 \mathrm{sec}, 60^{\circ} \mathrm{C}$ for $30 \mathrm{sec}$ and $95^{\circ} \mathrm{C}$ for $15 \mathrm{sec}$ and were performed in 7300 Real-Time PCR System from Applied Biosystems (Foster City, CA).

Data analysis. Transcript levels were obtained from qRT-PCR analysis using the $2^{-\triangle \mathrm{CT}}$ method (19), and were presented as relative expression of the gene of interest and the reference gene. Data were expressed as mean of $2^{-\Delta \mathrm{CT}} \pm$ standard deviation. For statistical analysis the paired Student's t-test was used, with the GraphPad Prism 5.0 software. A P-value $<0.05$ was considered statistically significant.

\section{Results}

Echocardiographic examination showed infarction of the left ventricular anterior and lateral walls in experimental mice group (Fig. 1B), validating the model used in this study. 
Table I. Primer sequences used in this study.

\begin{tabular}{|c|c|c|c|}
\hline Gene & Alternative name & Primer & Reference \\
\hline CXCL12 & SDF-1 & $\begin{array}{l}\text { Forward: TGAGGCCAGGGAAGAGTGAG } \\
\text { Reverse: GACACATGGCGATGAATGGA }\end{array}$ & 17 \\
\hline IL-6 & & $\begin{array}{l}\text { Forward: TTCCATCCAGTTGCCTTC } \\
\text { Reverse: TTCTCATTTCCACGATTTCC }\end{array}$ & 18 \\
\hline CCL7 & MCP-3 & $\begin{array}{l}\text { Forward: CTCATAGCCGCTGCTTTCAG } \\
\text { Reverse: ACAGCTTCCCAGGGACACCGA }\end{array}$ & \\
\hline CXCL2 & MIP-2 & $\begin{array}{l}\text { Forward: CGCCCAGACAGAAGTCATAG } \\
\text { Reverse: TCCTCCTTTCCAGGTCAGTTA }\end{array}$ & 19 \\
\hline CCL2 & MCP-1 & $\begin{array}{l}\text { Forward: TTAACGCCCCACTCACCTGCTG } \\
\text { Reverse: GCTTCTTTGGGACACCTGCTGC }\end{array}$ & 20 \\
\hline CCL3 & MIP-1A & $\begin{array}{l}\text { Forward: TGAATGCCTGAGAGTCTTGG } \\
\text { Reverse: TTGGCAGCAAACAGCTTATC }\end{array}$ & 19 \\
\hline CCL4 & MIP-1B & $\begin{array}{l}\text { Forward: TGCCCTCTCTCTCCTCTTGCT } \\
\text { Reverse: CAGGAAGTGGGAGGGTCAGA }\end{array}$ & 21 \\
\hline CCL8 & MCP-2 & $\begin{array}{l}\text { Forward: GTGCTTCTTTGCCTGCTGCTCATA } \\
\text { Reverse: AGACATACCCTGCTTGGTCTGGAA }\end{array}$ & 22 \\
\hline CXCL10 & IP-10 & $\begin{array}{l}\text { Forward: GAAATCATCCCTGCGAGCCT } \\
\text { Reverse: TTGATGGTCTTAGATTCCGGATTC }\end{array}$ & 23 \\
\hline CX3CL1 & Fractalkine & $\begin{array}{l}\text { Forward: ACGAAATGCGAAATCATGTGC } \\
\text { Reverse: CTGTGTCGTCTCCAGGACAA }\end{array}$ & 24 \\
\hline HPRT & & $\begin{array}{l}\text { Forward: AATTATGGACAGGACTGAAAGACTTGCT } \\
\text { Reverse: TCCAGCAGGTCAGCAAAGAATTTATAGC }\end{array}$ & \\
\hline
\end{tabular}

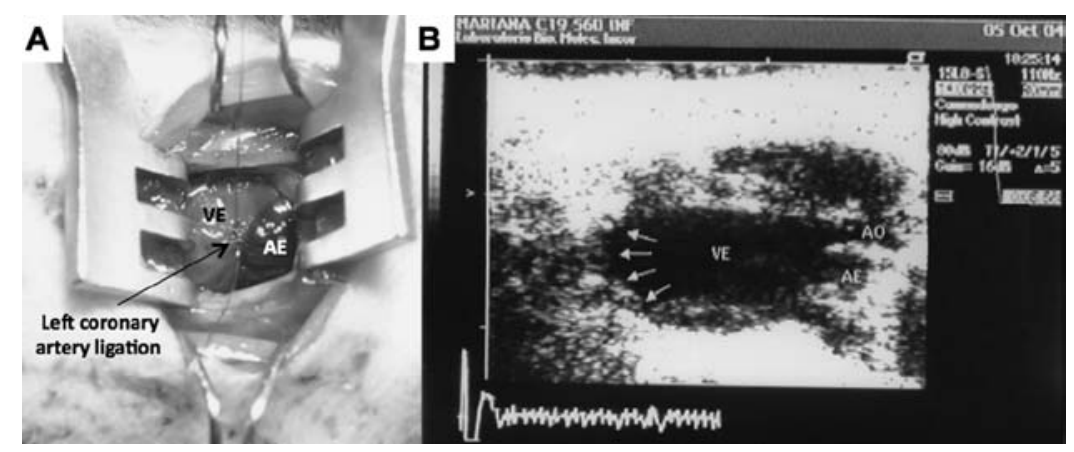

Figure 1. (A) Photography of the myocardial infarction procedure. The arrow indicates the left coronary artery ligation. (B) Echocardiogram of an infarcted mouse. Arrows indicate the myocardial infarcted area of the left ventricular wall. VE, left ventricle; AE, left atrium; AO, aorta.

Most of the chemokine $\mathrm{CC}$ motif ligand genes investigated had their expression markedly increased in the acute phase of infarction, after $24 \mathrm{~h}$ of ischemia. Expression of CCL2, CCL3 and CCL4 was increased 19-fold, 7.8-fold and 25.2-fold, respectively (Fig. 2). For CCL7, a 36-fold increase was observed (Fig. 3A). Gene expression returned to baseline levels 30 days after ischemia, without significant differences compared to non-ischemic control samples. Expression of the CCL8 gene, on the other hand, showed no significant increase after $24 \mathrm{~h}$ of ischemia, but was increased 4.3 -fold after 30 days of MI (Fig. 3B).
The response of CXCL genes to infarction was more variable. At $24 \mathrm{~h}$, a marked increase of expression (610.5-fold) was observed for the CXCL2 gene, whereas CXCL10 expression showed a more discrete increase (3.4-fold) and expression of CXCL12 was not modified (Fig. 4). In all cases, gene expression 30 days after infarction was similar to that of control samples.

Expression of the IL-6 gene was significantly increased in the acute phase (53.5-fold) as well as in the chronic phase (9.8-fold) of MI (Fig. 5A). Expression of the CX3CL1 gene was not modified by the experimental procedure (Fig. 5B). 

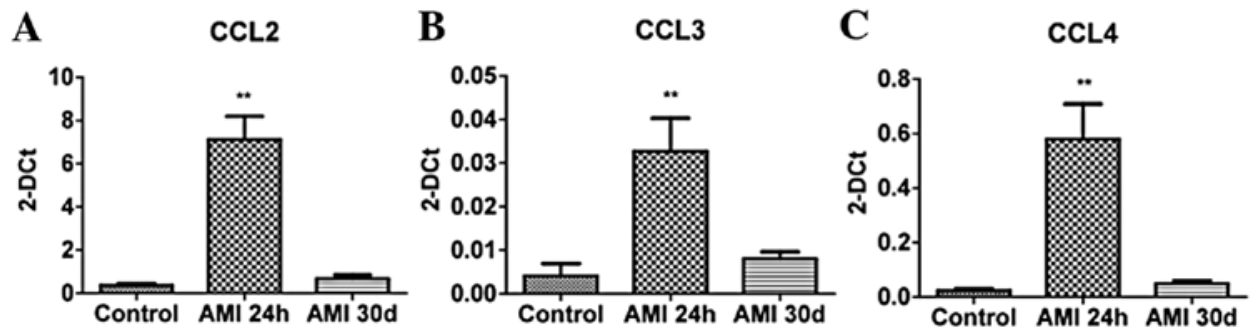

Figure 2. (A) In the acute phase of infarction $(24 \mathrm{~h})$, CCL2 expression was increased 19.0-fold ( $\mathrm{P}<0.01)$, and 30 days later it was 1.8 -fold higher than in control samples (not significant). (B) CCL3 expression was increased 7.8-fold $24 \mathrm{~h}$ after infarction $(\mathrm{P}<0.01)$, but on day 30 the increase (1.9-fold) was non-significant. (C) CCL4 was increased by 25.2 -fold ( $\mathrm{P}<0.01)$ after $24 \mathrm{~h}$ and returned to basal levels at 30 days (2.1-fold). AMI, acute myocardial infarction.
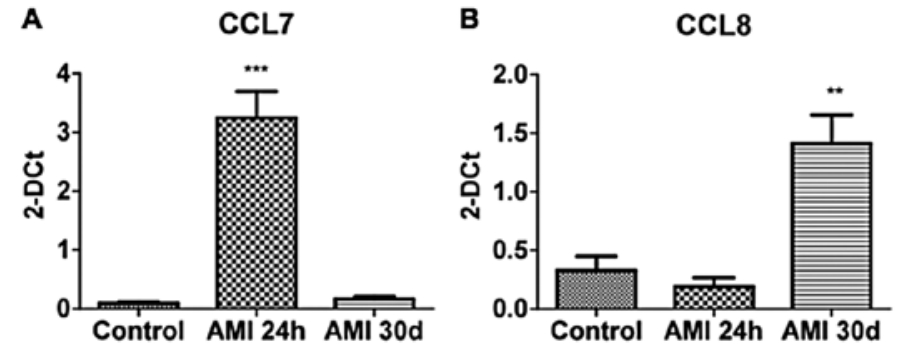

Figure 3. (A) After $24 \mathrm{~h}$ of cardiac ischemia, the expression of CCL7 was 36.0 -fold higher than in healthy control mice ( $\mathrm{P}<0.001)$. After 30 days of ischemia, the expression was 1.8-fold higher, not significantly different compared to the control. (B) After $24 \mathrm{~h}$ of AMI, the expression of CCL8 was similar to control samples (-1.7-fold), but after 30 days it showed a 4.3 -fold significant increase $(\mathrm{P}<0.01)$. AMI, acute myocardial infarction.
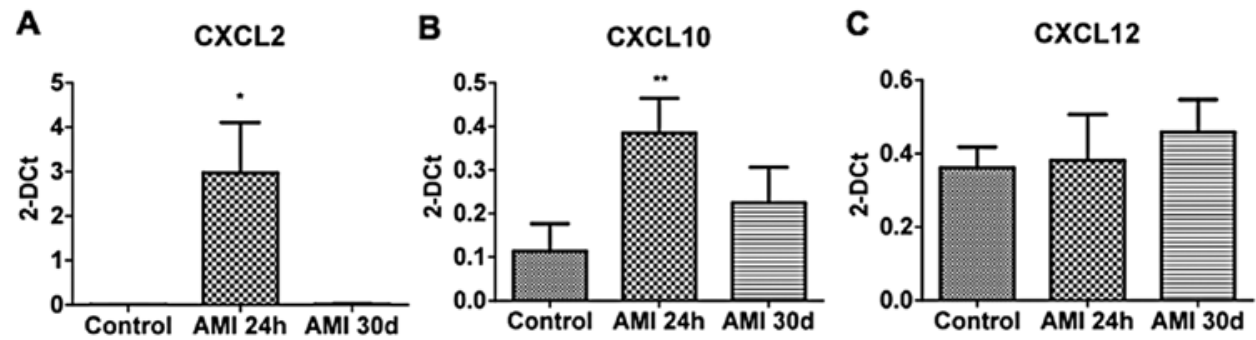

Figure 4. (A) In the acute phase of myocardial infarction, CXCL2 showed the highest elevation in expression among the genes analyzed (610.5-fold) as compared to control samples ( $\mathrm{P}<0.05)$. After 30 days a non-significant increase of 3.8-fold was observed. (B) Expression of CXCL10 increased 3.4-fold after $24 \mathrm{~h}$ of infarction $(\mathrm{P}<0.01)$, and decreased to basal levels after 30 days ( 2.0 -fold, not significant). (C) Expression of CXCL12 showed a non-significant increase of 1.8 and 1.5 -fold after $24 \mathrm{~h}$ and 30 days of myocardial infarction, respectively. AMI, acute myocardial infarction.

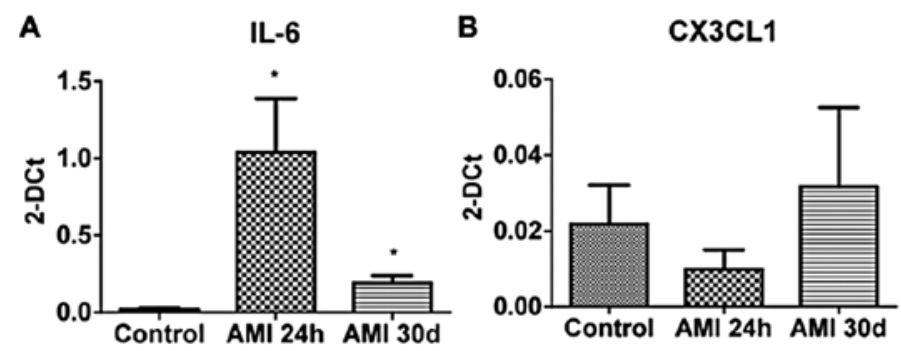

Figure 5. (A) Expression of IL-6 was increased 53.5-fold after $24 \mathrm{~h}$ of infarction, compared with control, $\mathrm{P}<0.05$. After 30 days, this expression was greatly reduced, but was still significantly higher (9.8-fold) than in control samples ( $\mathrm{P}<0.05)$. (B) Expression of CX3CL1 was not modified after $24 \mathrm{~h}$ and 30 days of myocardial infarction. AMI, acute myocardial infarction.

\section{Discussion}

In this study, we analyzed the expression of genes coding for cytokines and chemokines in the acute and chronic phases of
MI in C57BL/6 mice. Expression of 6 of the 10 genes investigated in this study (CCL2, CCL3, CCL4, CCL7, CXCL2 and CXCL10) showed significant increase in the acute phase of MI, and reverted to baseline levels after 30 days. For CCL2 and 
CCL3, the increase was 19.0-fold and 7.8-fold, respectively that of control samples. Similar results have been reported by Parissis et al (20), who observed that plasma levels of these proteins were transiently increased in patients admitted with MI. The increased protein levels seen during the first week reverted to baseline levels in most of the patients after 14 days. Increased expression of CCL2 and CCL3 were also observed in a murine model of MI, between 2 and 7 days, and $6 \mathrm{~h}$ and 7 days, respectively (13). Other studies, however, have shown different results. In one, plasma levels of CCL2 were not significantly increased in MI patients (21), whereas in a second study, decreased plasma levels of CCL3 and CCL4 were observed in patients with ST-segment elevation MI followed by reperfusion, in periods of 2, 7 and 60 days (22). In terms of CCL4, whereas our results show an increased expression $24 \mathrm{~h}$ after infarction, in a similar study this increase was observed only 3 days later (14).

Expression of CCL7 in the acute phase of MI was 36-fold higher than in control samples. Few studies have been conducted focusing on this chemokine, which has already been shown to attract MSC in migration assays as well as induced MI models (23). Furthermore, genetic modification of MSC with the CCR1 gene (CCL7 receptor) was shown to increase the viability, recruitment and retention of those cells in the MI regenerative niche (24). Plasma levels of CCL7, however, were not increased in MI patients (25).

In 24 h samples, CXCL2 expression was 610.5-fold higher than in control samples, in agreement with a previous study which showed that expression of CXCL2 was the highest among various cytokines and chemokines investigated in a murine model of MI (13). For CXCL10, a 3.4-fold increase was observed at $24 \mathrm{~h}$. Different results for the expression of this gene after MI have been reported. Husberg et al (14) observed a significant increase in the expression of CXCL10 only 3 days after infarction in a murine model, and a study with MI patients showed decreased plasma levels for this chemokine (22).

In the present study, chemokines CXCL12 (SDF-1) and CX3CL1 showed no increase in the expression $24 \mathrm{~h}$ or 30 days after MI. Controversial results have been reported on the expression of these genes in similar studies. CXCL12 is considered to play and important role in the recovery of MI (26-31), but its expression in the infarcted heart or in the plasma is not always high. In rats, CXCL12 was detected 1 day after infarction, peaking on day 7 and declining to basal levels around 14 days later (32). In mice, a slightly decreased gene expression of SDF-1, primarily located within the infarcted region, was reported (13). In humans, plasma levels of CXCL12 gradually decreased between 2, 7 and 60 days after MI (22). Although controversial, these studies do not alter the role that CXCL12 plays in the recovery of MI (26-31). In a recent study, it was observed that the overexpression of CXCR4 (SDF-1 receptor) enhanced MSC recruitment and penetration into the ischemic regenerative niche, resulting in more efficient tissue repair (33).

Expression of CX3CL1 has been shown to increase following MI. In mice, CX3CL1 was highly expressed at the gene and protein level, in experimental periods of 3,5 , 7 and 14 days after MI (14). In patients with acute coronary disease, plasma levels of CX3CL1 and its receptor CX3CR1 was increased $(22,34)$.
Contrary to all other chemokines investigated in the present study, expression of CCL8 was not modified in the acute period of MI, but showed a significant increase 30 days later (4.3 times). Although it has already been shown to increase after 5 and 7 days of myocardial induction, returning to basal levels on day 14 (14), few studies have investigated the pattern of expression of this chemokine after MI.

Finally, the increased expression of IL- 6 in the acute and chronic phases of MI when compared to healthy control is in agreement with a previous study of Deten et al (35), who showed the elevation of IL- 6 mRNA levels in periods from $3 \mathrm{~h}$ to 12 weeks after induction of MI in rats. Other studies, however, have shown different kinetics for the expression of the IL-6 gene. Vandervelde et al (13) observed a peak expression of IL-6 $6 \mathrm{~h}$ after coronary artery ligation, but this increase was maintained only up to 2 days. In another study, the expression of IL-6 was significantly increased only after 7 days of MI, having returned to baseline levels on day 14 (14). Interestingly, in patients with coronary artery disease the IL-6 gene does not seem to be a marker for this condition (36).

These considerations show that, despite the great number of studies aiming at the determination of the molecular profile of ischemic heart tissue, the picture is still very inconclusive. The more detailed knowledge of the regenerative niche in MI is important for the identification of sub-populations of cells with greater potential to respond to these signals and exert a more efficient therapeutic role. Alternatively, genetic modification of these cells may be used to increase their therapeutic potential (37). These studies will allow the design of more efficient cell therapy protocols for cardiac diseases.

\section{Acknowledgements}

This study was supported by the CNPq-MCT grant 574036/ 2008-3 and ULBRA.

\section{References}

1. Nardi NB: All the adult stem cells, where do they all come from? An external source for organ-specific stem cell pools. Med Hypotheses 64: 811-817, 2005.

2. Lodi D, Iannitti T and Palmieri B: Stem cells in clinical practice: applications and warnings. J Exp Clin Cancer Res 30: 9, 2011.

3. da Silva Meirelles L, Chagastelles PC and Nardi NB: Mesenchymal stem cells reside in virtually all post-natal organs and tissues. J Cell Sci 119: 2204-2213, 2006.

4. Burt RK, Loh Y, Pearce W, et al: Clinical applications of blood-derived and marrow-derived stem cells for nonmalignant diseases. JAMA 299: 925-936, 2008.

5. Illa-Bochaca I and Montuenga LM: The regenerative nidi of the locust midgut as a model to study epithelial cell differentiation from stem cells. J Exp Biol 209: 2215-2223, 2006.

6. Kirkpatrick JC, Fuchs S, Hermanns IM, Peters K and Unger RE: Cell culture models of higher complexity in tissue engineering and regenerative medicine. Biomaterials 28: 5193-5198, 2007.

7. Frangogiannis NG: The immune system and cardiac repair. Pharmacol Res 58: 88-111, 2008.

8. Menasche P: Stem cell: where we stand. Dialog Cardiovasc Med 3: 123-133, 2003.

9. Mukherjee D, Lingam P, Chetcuti S, et al: Missed opportunities to treat atherosclerosis in patients undergoing peripheral vascular interventions: insights from the University of Michigan Peripheral Vascular Disease Quality Improvement Initiative (PVD-QI2) Circulation 106: 1909-1912, 2002.

10. Meirelles LdaS, Fontes AM,Covas DT and Caplan AI: Mechanisms involved in the therapeutic properties of mesenchymal stem cells. Cytokine Growth Factor Rev 20: 419-427, 2009. 
11. Frangogiannis NG: Chemokines in the ischemic myocardium: from inflammation to fibrosis. Inflamm Res 53: 585-595, 2004.

12. Braunersreuther V, Mach F and Steffens S: The specific role of chemokines in atherosclerosis. Thromb Haemost 97: 714-721, 2007.

13. Vandervelde $\mathrm{S}$, van Luyn MJ, Rozenbaum $\mathrm{MH}$, Petersen $\mathrm{AH}$, Tio RA and Harmsen MC: Stem cell-related cardiac gene expression early after murine myocardial infarction. Cardiovasc Res 73: 783-793, 2007.

14. Husberg C, Nygard S, Finsen AV, et al: Cytokine expression profiling of the myocardium reveals a role for CX3CL1 (fractalkine) in heart failure. J Mol Cell Cardiol 45: 261-269, 2008.

15. Vilahur G, Juan-Babot O, Peña E, Oñate B, Casaní L and Badimon L: Molecular and cellular mechanisms involved in cardiac remodeling after acute myocardial infarction. J Mol Cell Cardiol 50: 522-533, 2011.

16. de Macedo Braga LM, Lacchini S, et al: In situ delivery of bone marrow cells and mesenchymal stem cells improves cardiovascular function in hypertensive rats submitted to myocardial infarction. J Biomed Sci 15: 365-374, 2008

17. Braga LM, Rosa K, Rodrigues B, et al: Systemic delivery of adult stem cells improves cardiac function in spontaneously hypertensive rats. Clin Exp Pharmacol Physiol 35: 113-119, 2008.

18. Nozawa E, Kanashiro RM, Murad N, et al: Performance of twodimensional Doppler echocardiography for the assessment of infarct size and left ventricular function in rats. Braz J Med Biol Res 39: 687-695, 2006.

19. Schmittgen TD and Livak KJ: Analyzing real-time PCR data by the comparative CT method. Nat Protoc 3: 1101-1108, 2008.

20. Parissis JT, Adamapoulos S, Vanetsanou KF, Mentzikof DG, Karas SM and Kremastinos DT: Serum profiles of C-C chemokines in acute myocardial infarction: possible implication in postinfarction left ventricular remodeling. J Interferon Cytokine Res 22: 223-229, 2002.

21. De Jager SC, Kraaijeveld AO, Grauss RW, et al: CCL3 (MIP-1 $\alpha$ ) levels are elevated during acute coronary syndromes and show strong prognostic power for future ischemic events. J Mol Cell Cardiol 45: 446-452, 2008.

22. Orn S, Breland UM, Mollnes TE, Manhenke K, Aukrust P and Ueland T: The chemokine network in relation to infarct size and left ventricular remodeling following acute myocardial infarction. Am J Cardiol 104: 1179-1183, 2009.

23. Schenk S, Mal N, Finan A, Zhang M, Kiedrowski M, Popovic Z, Mccarthy PM and Penn MS: Monocyte chemotatic protein-3 is a myocardial mesenchymal stem cell homing factor. Stem Cells 25: 245-251, 2007.

24. Huang J, Zhang Z, Guo J, et al: Genetic modification of mesenchymal stem cells overexpressing CCR1 increases cell viability, migration, engraftment, and capillary density in the injured myocardium. Circ Res 106: 1753-1762, 2010.

25. Ardigo D, Assimes TL, Fortmann SP, et al: Advance Investigators. Circulating chemokines accurately identify individuals with clinically significant atherosclerotic heart disease. Physiol Genomics 31: 402-409, 2007
26. Czarnowska E, Gajerska-Dzieciatkowska M, Kusmierski K, et al: Expression of SDF-1-CXCR4 axis and an anti-remodelling affectiveness of foetal-liver stem cell transplantation in the infarcted rat heart. J Physiol Pharmacol 58: 729-744, 2007.

27. Zhang G, Nakamura Y, Wang X, Hu Q, Suggs LJ and Zhang J: Controlled release of stromal cell-derived factor-1 alpha in situ increases $\mathrm{C}-\mathrm{kit}^{+}$cell homing to the infarcted heart. Tissue Eng 13: 2063-2071, 2007.

28. Lin HH, Chen YH, Chang PF, Lee YT, Yet SF and Chau LY: Heme oxygenase-1 promotes neovascularization in ischemic heart by coinduction of VEGF and SDF-1. J Mol Cell Cardiol 45: 44-55, 2008.

29. Saxena A, Fish JE, White MD, et al: Stromal cell-derived factor-1a is cardioprotective after myocardial infarction. Circulation 117: 2224-2231, 2008.

30. Stich S, Haag M, Haupl T, Sezer O, Notter M, Kaps C, Sittinger M and Ringe J: Gene expression profiling of human mesenchyma stem cells chemotactically induced with CXCL12. Cell Tissue Res 336: 225-236, 2009.

31. Hiesinger W, Vinogradov SA, Atluri P, et al: Oxygen-dependent quenching of phosphorescence used to characterize improved myocardial oxygenation resulting from vasculogenic cytokine therapy: J Appl Physiol 110: 1460-1465, 2011.

32. Zhuang Y, Chen X, Xu M, Zhang LY and Xiang F: Chemokine stromal cell-derived factor 1/CXCL12 increases homing of mesenchymal stem cells to injured myocardium and neovascularization following myocardial infarction. Chin Med J 22: 183-187, 2009.

33. Zhang D, Huang W, Dai B, Zhao T, Ashraf A, Millard RW, Ashraf $M$ and Wang Y: Genetically manipulated progenitor cell sheet with diprotin A improves myocardial function and repair of infarcted hearts. Am J Physiol Heart Circ Physiol 299: H1339-H1347, 2010

34. Damas JK, Boullier A, Waehre T, et al: Expression of fractalkine (CX3CL1) and its receptor, CX3CR1, is elevated in coronary artery disease and is reduced during statin therapy. Arterioscler Thromb Vasc Biol 25: 2567-2572, 2005.

35. Deten A, Volz HC, Briest W and Zimmer HG: Cardiac cytokine expression is upregulated in the acute phase after myocardial infarction. Experimental studies in rats. Cardiovasc Res 55: 329-340, 2002

36. Kirbis S, Breskvar UD, Sabovic M, Zupan I and Sinkovic A: Inflammation markers in patients with coronary artery disease - comparison of intracoronary and systemic levels. Wien Klin Wochenschr 122: 31-34, 2010.

37. Rota M: SDF-1 axis and myocardial infarction. Am J Physiol Heart Circ Physiol 299: H1307-H1308, 2010. 